\title{
Monitoring stress in captive and free-ranging African wild dogs (Lycaon pictus) using faecal glucocorticoid metabolites
}

\author{
L. K. Van der Weyde ${ }^{1,2}$, G.B. Martin ${ }^{1}$ and M.C.J. Paris ${ }^{1,2}$
}

\footnotetext{
${ }^{1}$ School of Animal Biology M085, University of Western Australia, Crawley 6009, Australia

${ }^{2}$ Institute for Breeding Rare and Endangered African Mammals (IBREAM), Mammal Research Institute, University of Pretoria, GT, South Africa
}

Contact author: Leanne Van der Weyde email: leannevdw@gmail.com

\section{Abstract}

An understanding of stress physiology is important for species management because high levels of stress can hamper reproduction and affect an individual's ability to cope with threats to their survival, such as disease and human-wildlife conflict. A commonly used indicator of stress, faecal concentrations of cortisol metabolites (FCM), can be used to assess the impact of social, biological and environmental factors. Measurements of FCM are particularly valuable for endangered species that are logistically challenging to study and where non-invasive techniques are preferred. As the second most endangered canid in Africa, the African wild dog (Lycaon pictus) has been the focus of considerable conservation research, yet there is still little understanding of factors associated with stress, in either captive or free-ranging populations. The present study therefore aimed to determine whether stress levels differ between captive and free-ranging populations, and to detect social, biological and environmental factors that are stressful in these populations. Faecal samples were collected from 20 captive and 62 free-ranging animals. Within free-ranging populations, the sexes differed significantly, but there was no effect of social status, age or breeding period for either sex. Captive females had higher FCM concentrations than free-ranging females. In captive populations, FCM concentrations differed among zoos and with reproductive status in females, but were not related to age class or group-housing structure. In conclusion, FCM is a useful indicator of stress and should be considered an integrative aspect of management, for both in-situ and ex-situ African wild dog populations.

Keywords: radioimmunoassay, reproduction, conservation, endangered, zoo 


\section{Introduction}

An individual's response to stressful factors has important ramifications for their ability to survive and reproduce. An acute stress response leading to a release of glucocorticoids (GC) does not normally affect the health status of an individual and may even be beneficial, provided the individual can rapidly regain homeostasis (Asa, 2010; Keay et al., 2006; Moberg, 1985). On the other hand, the well-known adverse effects of stress on reproductive health (Matteri et al., 2000; Moberg, 1985; Rivier and Rivest, 1991; Wingfield and Sapolsky, 2003) are associated with long-term production of GC (Ladewig, 2000; Moberg, 2000; Tilbrook et al., 2000). The outcomes include disruption of ovulation and expression of sexual behaviour, inhibition of embryo implantation and reductions in sex hormone production (Moberg, 1985; Rivier and Rivest, 1991; Wingfield and Sapolsky, 2003). These negative consequences for reproduction can be critical for individuals and for populations, so it is important to detect and mitigate highly stressful social, environmental or biological factors, particularly in the management of endangered species (Millspaugh and Washburn, 2004).

The management of endangered species varies considerably between captive and free-ranging populations because it is difficult to mimic the natural environmental and social conditions for exsitu populations. Thus, when examining GC patterns in these populations, it is essential to consider different potential causes of stress. For example, captive individuals face no threat from predators and are not exposed to the daily stress of finding food and shelter, but instead may experience negative social interactions due to confined space and lack of cover. In a study of captive clouded leopards (Neofelis nebulosa), where reproductive success in captivity has been poor, Wielebnowski et al. (2002) observed increased GC concentrations in individuals with small enclosure heights and limited keeper contact. Alternatively, anthropogenic factors, such as human activity from roads and villages, could be a source of stress in free-ranging but not captive populations (Bhattacharjee et al., 2015; Creel et al., 2002; Van Meter et al., 2009). It is difficult to determine whether stressors in captivity are more severe than those in a free-ranging environment, particularly as some individuals may cope with stress better than others (Ladewig, 2000; Millspaugh and Washburn, 2004; Sapolsky, 1994), and repeated exposure may diminish stress responses through habituation (Ladewig, 2000). However, in studies with cheetah (Acinonyx jubatus), Canada lynx (Lynx canadensis), spider monkeys (Ateles geoffroyi) and sparrows (Zonotrichia spp.), GC concentrations were higher in captive than in free-ranging individuals (Fanson et al., 2011; Marra et al., 1995; Rangel-Negrin et al., 2009; Terio et al., 2004). If the level of stress is indeed higher in captive animals than in free-ranging animals, then 
it might help explain poor reproductive success in captivity in some species (Carlstead and Shepherdson, 1994).

African wild dogs (Lycaon pictus) are highly social, cooperative breeders. Reproduction is typically restricted to the dominant pair who maintain their dominance through displays of aggression associated with submission by subordinates (Creel et al., 1997a; Frame et al., 1979). In previous studies, dominant individuals were found to have higher faecal GC concentrations than subordinates throughout the year (Creel et al., 1997a), an observation that was initially counter-intuitive and led to the suggestion that GCs are not mediators of reproductive suppression (Barja et al., 2008; Creel, 2005). High GC values in dominants might have been explained by aggression, but Creel (2005) considered this unlikely and concluded that aggression alone could not explain the persistence of high concentrations throughout the year because most aggression is confined to the mating period. Therefore, although aggression is likely to induce an acute stress response, adrenal activity is still poorly understood in African wild dogs. Most other studies of GC patterns in this species have been limited to the effects of immobilisation, handling and translocation (Comizzoli et al., 2009; Creel et al., 1997b; de Villiers et al., 1995; de Villiers et al., 1997), so further investigations into potential biological causes of chronic stress in both captive and free-ranging populations are still needed.

In the present study, we chose to measure GC non-invasively in collected faeces because this approach would minimise our potential effect on stress levels. We focused on the metabolites that have previously been measured in African wild dogs (de Villiers et al., 1995; de Villiers et al., 1997; Monfort et al., 1998; Santymire and Armstrong, 2009) and that are commonly used to asses stress (Touma and Palme, 2005). We hypothesised that faecal concentrations of GC metabolites in wild dogs would a) be higher in captive than in free-ranging animals, as found in previous studies, b) vary with conditions of captivity; and c) be affected by age and reproductive status, in both captive and free-ranging animals.

\section{Methods}

\subsection{Animals and sample collection}

Faecal samples were collected from captive female wild dogs in five zoos in either 2008 or 2009 in Europe (Artis Zoo, Port Lympne Wild Animal Park, West Midland Safari and Leisure Park and Zoo Duisburg) during the reproductive season (June to November) and Australia (Perth Zoo) at the end of the reproductive season (June). No samples were collected from males because too few animals 
were available during the study period. The collection protocol used in European zoos has been described previously (Van der Weyde et al., 2015) and a similar protocol was followed in Australia. For free-ranging animals, faecal samples were collected opportunistically from up to eight packs in Hluhluwe-iMfolozi Park (South Africa), during the reproductive season (February to July) in 2010 and 2011. At least one individual per pack was VHF-radio-collared to allow regular tracking of the pack when they were in vehicle-accessible areas. Most packs ranged in areas within the park that included roads and human activity, and only a couple of packs ranged in areas with limited vehicle access. These packs have been followed intensively for several years, so all individuals could be identified and their ages to the nearest month were known (range $0.6-10$ y). Packs were followed from a vehicle and samples from identified individuals were collected within 15 min of defecation and stored for $0.5-4 \mathrm{~h}$ on ice until frozen. For each sample, the time of day, delay to freezing, date, individual ID and pack ID were recorded. A total of 531 samples were used for analysis, comprising 297 from captive females $(n=20), 96$ from free-ranging females $(n=18)$ and 138 from free-ranging males $(n=44)$.

\subsection{Faecal extractions}

The extraction method for samples from captive animals has been described previously (Van der Weyde et al., 2015). Logistical issues made transporting frozen samples from free-ranging populations difficult, so samples were first oven dried over low heat in the field and then transported to Australia before extraction. In brief: $0.25 \mathrm{~g}$ wet sample was weighed into a plastic tube, vortexed with $4 \mathrm{~mL} 100 \%$ methanol for $20 \mathrm{~min}$, and then centrifuged for $20 \mathrm{~min}\left(4^{\circ} \mathrm{C}, 3000 \mathrm{~g}\right)$. The supernatant was decanted into clean glass tubes, dried under air, capped and stored at $-20^{\circ} \mathrm{C}$ until assay.

\subsection{Cortisol radioimmunoassay}

Cortisol was assayed using a GammaCoat Cortisol ${ }^{125} I$ kit (DiaSorin, North Ryde, Australia). Major cross-reactions were: cortisol (100\%), prednisolone (25.5\%), 6-methylprednisolone (14.5\%), cortisone (10.3\%), 11-deoxycortisol (9.8\%), 63-hydrocortisone (4.2\%) and prednisone (3.8\%); all other cross-reactions were below $1 \%$. We followed kit instructions except that we doubled the volume of standards and extracts and added three extra standards $(1.25,2.5$ and $5 \mathrm{ng} / \mathrm{mL}$ ) below the minimum provided by the kit using kit products. Extracted samples were reconstituted with $1 \mathrm{~mL}$ 100\% methanol, sonicated for $20 \mathrm{sec}$ and vortexed briefly before being diluted 1:2-1:5 in phosphate buffer. Three samples were diluted at several volumes to demonstrate parallelism with the standard curve. Sensitivity was $<1.25 \mathrm{ng} / \mathrm{mL}$ and the limit of detection ranged from 3.9-17.9 ng/g. The intra- 
assay coefficient of variation was $14 \pm 3.9 \%(n=9)$ and the inter-assay coefficient of variation was $13.2 \%, 11.5 \%$ and $26.2 \%$ for high, medium and low concentrations, respectively. Cortisol is not present in wild dog faeces (Monfort et al., 1998) so results here are considered to represent faecal cortisol metabolite (FCM) concentrations (Palme, 2005).

\subsection{Data analysis}

Statistical analyses were aided by SPSS version 20.0 (SPSS Inc., IBM, Chicago, IL, USA). Linear mixed models (LMM) using maximum likelihood were used to compare FCM concentrations for three sets of analyses (Table 1). The table highlights the factors tested in each model and variables for each factor are described below. High values potentially resulting from acute stress responses could greatly influence the analysis, so all values greater than two standard deviations above the mean were removed from each dataset so the data reflected basal FCM concentrations. Multiple samples were collected from individuals (free-ranging mean $=3.8$; captive mean $=14.9$ ), so individual ID was included as a random factor to avoid pseudo-replication (Millar and Anderson, 2004). In addition, pack and year were also included as random factors, but removed from the model if not significant. The covariance structure used for random effects was scaled identity. Non-significant fixed factors were also removed one at a time, until only significant factors remained in the model. Reported means are estimated marginal means with standard errors. Normality and homogeneity of variance was checked by plotting residuals for each model. Significance was set at $p<0.05$. Pairwise comparisons used Least Significant Differences (LSD).

Table 1. Factors tested in each of the analyses using Linear Mixed Models

\begin{tabular}{ll}
\hline Analysis & Population differences \\
1 & Population \\
\hline 2 & Factors affecting free-ranging wild dogs \\
& Sex \\
& Social status +Age $(y)$ (Females and Males separately) \\
& Social status + Breeding period + Social status * Breeding period (Females and Males \\
& separately) \\
& Factors affecting captive wild dogs \\
& Reproductive status + Age class + Zoo + Group housing
\end{tabular}

To compare values in captive and free-ranging populations (Analysis 1, Table 1), it was necessary to correct wet sample concentrations for the wet and dried methods of hormone extraction. The correction factor was estimated by drying a random selection of wet samples $(n=34)$ from captive 
animals then extracting and assaying them following the same protocol as the samples from freeranging animals. Concentrations in dried samples were on average $1.53 \pm 0.12$ fold higher than concentrations in wet samples so values for captive females were multiplied by 1.53 , but only for comparison of these two populations.

For Analysis 2, the sexes were compared in free-ranging populations. The difference was highly significant so all subsequent analyses were separated by sex. Social status was separated into dominant, unrelated subordinate (siblings of the dominant individual and thus unrelated to opposite-sex members) or natal subordinate (individuals born into the pack and thus related to both males and females) classes. Age of each animal (y) was included as a covariate in the model. There were four breeding periods: non-breeding (before onset of the breeding season), mating (including pro-oestrus and oestrus periods using behavioural observations of the dominant pair), gestation (of the dominant female) and denning (post birth).

For Analysis 3, the factors were reproductive status (acyclic or cycling), where cycling included pregnant and pseudopregnant females as assessed in a previous study (Van der Weyde et al., 2015), age class (adult or yearling), zoo location and group housing structure (mixed-sex or single-sex). As these fixed factors were potentially non-independent, we checked for correlation of the terms used in the final model.

\section{Results}

\subsection{Analysis 1 - Population differences}

After values from captive females were adjusted for differences in extraction procedures, there was a significant difference between the populations $\left(F_{1,31.9}=4.57, p=0.04\right)$, with captive females $(249 \pm$ $10 \mathrm{ng} / \mathrm{g}$ ) overall having higher FCM than free-ranging females (212 $\pm 14 \mathrm{ng} / \mathrm{g}$ ).

\subsection{Analysis 2 - Factors affecting free-ranging wild dogs}

For free-ranging populations, FCM concentrations differed significantly between the sexes $\left(F_{1,24.6}=\right.$ $10.71, p=0.003$ ). Despite analysing the sexes separately, social status categories (controlled for age of individual) had no effect on FCM values $\left(F_{2,92}=1.66, p=0.20\right.$ for females; $F_{2,22.8}=0.24, p=0.79$ for males). In both sexes, subordinates that were born in the pack had the highest overall FCM concentrations ( $243 \pm 24 \mathrm{ng} / \mathrm{g}$ for females; $163 \pm 17 \mathrm{ng} / \mathrm{g}$ for males), but dominant males (152 \pm 22 $\mathrm{ng} / \mathrm{g}$ ) had higher concentrations than unrelated subordinates $(142 \pm 21 \mathrm{ng} / \mathrm{g})$, whereas the reverse 


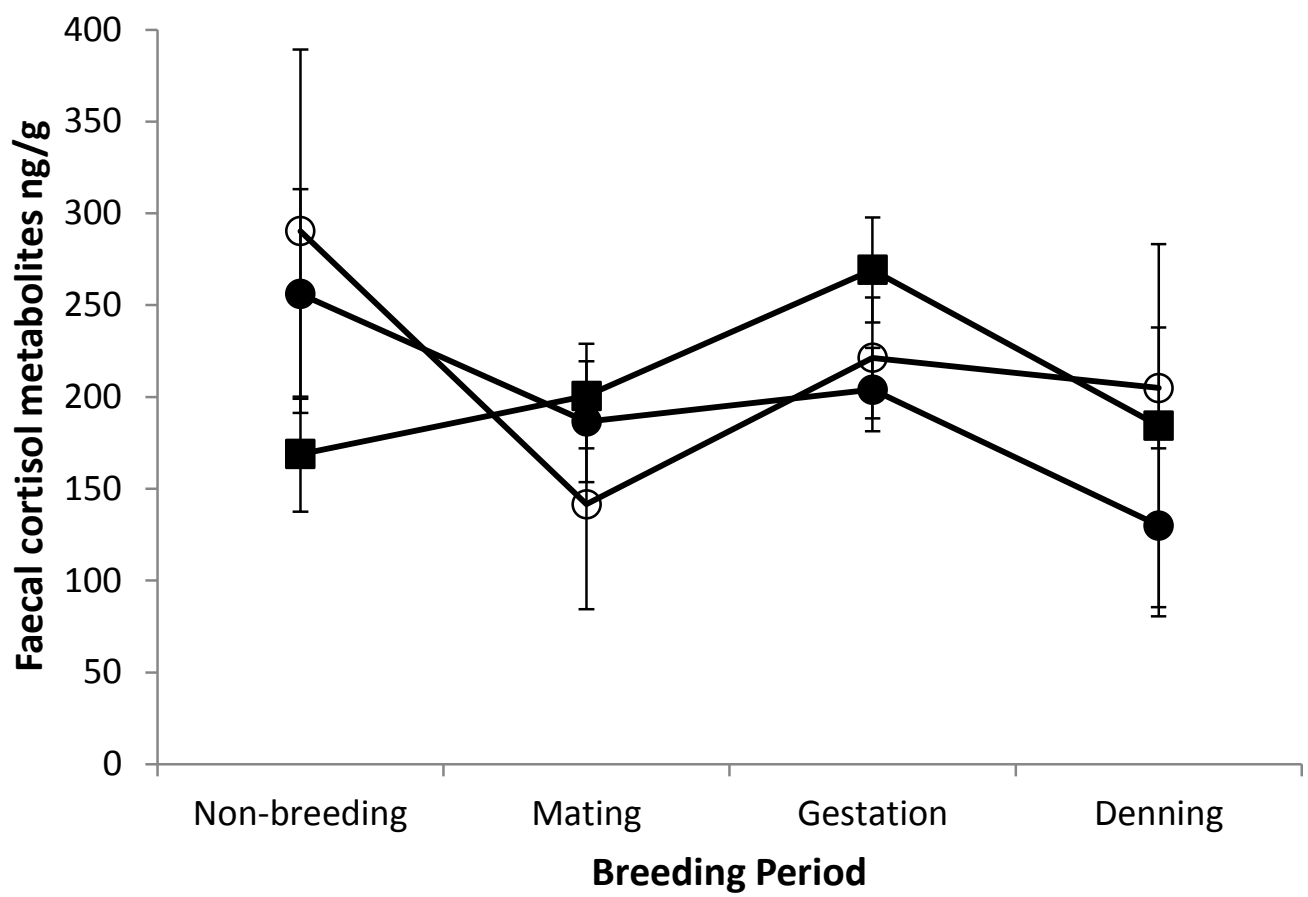

B

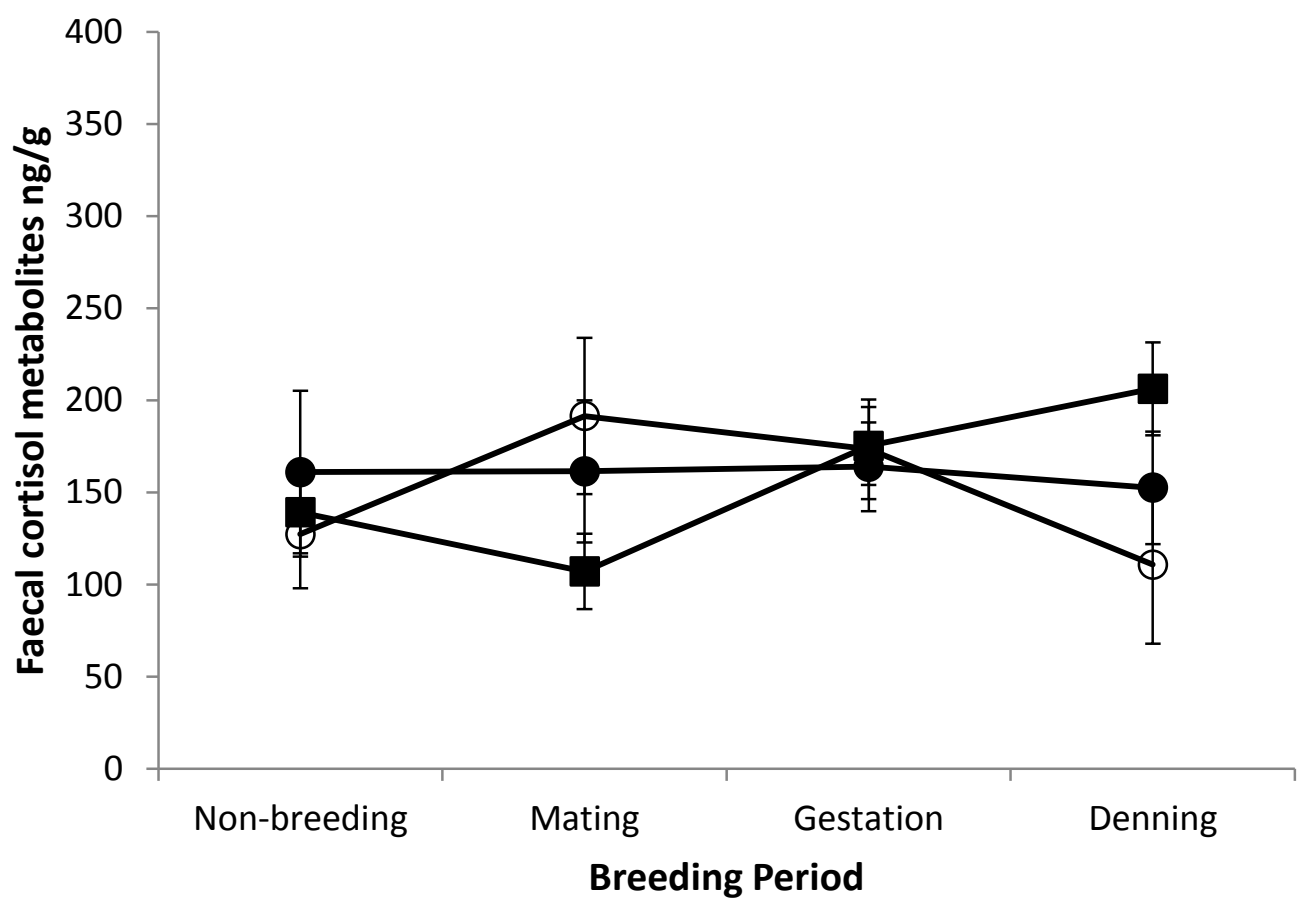

Figure 1. Faecal cortisol metabolite concentrations in female (A) and male (B) free-ranging African wild dogs in three categories of social status (Dominants - black circle; subordinates unrelated to opposite sex members - white circle and subordinates natal to the pack - black square) during the breeding season. Data show estimated marginal means \pm s.e.m. 
was true for females (dominants $173 \pm 22 \mathrm{ng} / \mathrm{g}$; unrelated subordinates $197 \pm 23 \mathrm{ng} / \mathrm{g}$ ). When breeding period was assessed with social status, neither showed any relationship with FCM concentrations. Although there was no significant interaction between social status and breeding period for either females $\left(F_{6,92}=1.21, p=0.31\right)$ or males $\left(F_{6,130.5}=1.58, p=0.16\right)$, the patterns varied between the sexes (Figure 1). Changes in FCM concentrations were most evident in subordinates which were not related to opposite sex members, particularly from non-breeding to mating periods.

\subsection{Analysis 3 - Factors affecting captive wild dogs}

For captive females, age class and group-housing structure did not significantly affect FCM concentrations and were dropped from the model. Reproductive status was a significant factor affecting FCM concentrations $\left(F_{1,287}=4.97, p=0.03\right)$. Individuals classified as cycling $(170 \pm 6 \mathrm{ng} / \mathrm{g})$ had higher FCM concentrations than those classified as acyclic (148 $\pm 10 \mathrm{ng} / \mathrm{g}$ ). There were also significant differences among zoos $\left(F_{4,287}=8.78, p<0.01\right.$; Figure 2). Pair-wise comparisons revealed that individuals in zoo 3 had significantly higher FCM concentrations $(216 \pm 12 \mathrm{ng} / \mathrm{g})$ than all other zoos. Zoo 5 individuals had the lowest FCM concentrations overall (116 $\pm 16 \mathrm{ng} / \mathrm{g})$, with levels significantly below zoo 1 and $3(p<0.05)$, but not with zoo $2(p=0.06)$ or zoo $4(p=0.08)$. Correlation coefficients between these fixed factors were low (below 0.3).

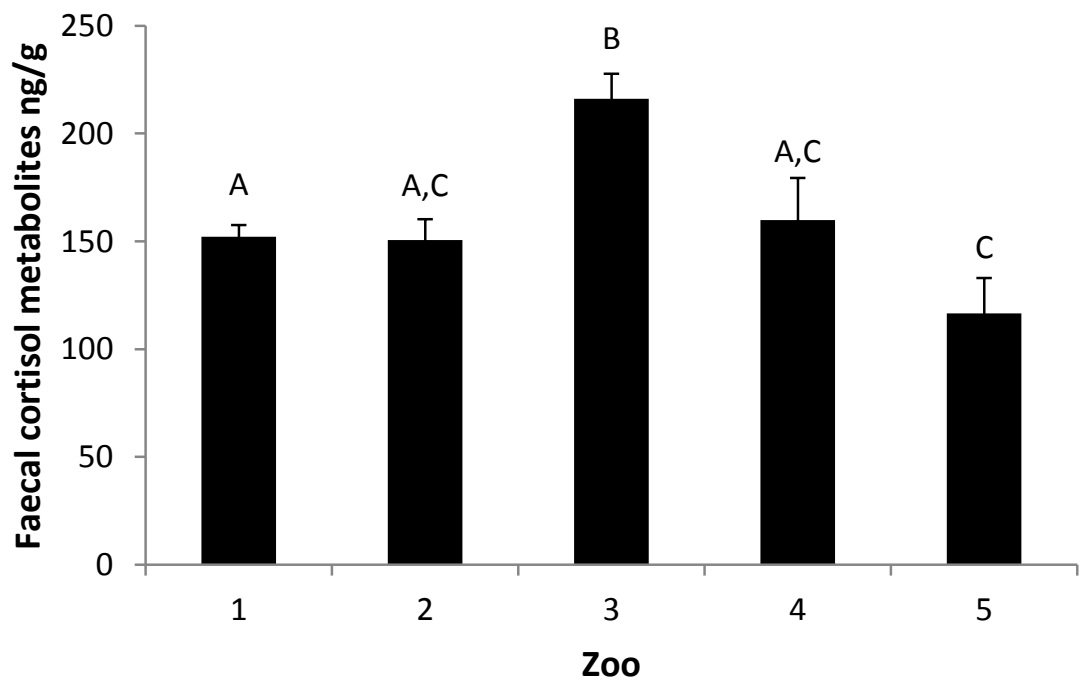

Figure 2. Mean faecal cortisol metabolite concentrations of captive female wild dogs from five different zoos. Data show estimated marginal means \pm s.e.m. Letters correspond to significant differences between the zoos.

\section{Discussion}

The faecal cortisol radioimmunoassay used in this study was able to detect variation in FCM concentrations between populations and among the various social, biological and environmental 
factors. The FCM values provide strong evidence that captive female wild dogs have higher levels of stress than free-ranging wild dogs, as seen in studies of other carnivores (Fanson et al., 2011; Terio et al., 2004). Among the factors that are thought to cause chronic stress in captive mammals, the evidence is strong for noise (Owen et al., 2004), social instability (Peel et al., 2005), on-exhibit display (Terio et al., 2004; Wielebnowski et al., 2002) and the reproductive status of females (Fanson et al., 2011). Pregnancy is energetically costly to females (Creel and Creel, 1991) so it is not surprising that FCM concentrations were higher in pregnant and, interestingly, pseudo-pregnant females, than in acyclic females, and our observations thus agree with those reported previously in other species (Kenagy and Place, 2000; Weingrill et al., 2004). Zoo also influenced FCM concentrations in captive females. We did not assess specific differences among zoos in husbandry practices (eg, diet, enclosure size, handling, keeper contact) due to small sample size, so can only conclude that variation among zoos appears to affect adrenal activity in wild dogs. However, determining which husbandry factors potentially induce stress within captivity deserves more attention. Housing as mixed pairs or single-sex groups did not affect FCM levels, an important finding because many zoos need to house their wild dogs as single-sex groups (L Van der Weyde, personal observation).

In free-ranging African wild dogs, FCM concentrations were higher in females than males, as reported previously for this species (Creel et al., 1997b) and several others (Keay et al., 2006; Millspaugh and Washburn, 2004; Touma and Palme, 2005). In wild dogs, the sexes play similar roles in hunting, defence, and rearing of offspring (Creel and Creel, 2002; Frame et al., 1979; Malcom and Marten, 1982), suggesting that the effect of sex on FCM values is most likely the result of differences in physiology (Tilbrook et al., 2000; Touma and Palme, 2005) rather than behaviour. Interestingly, in contrast to the reports by Creel et al. (1997a), we did not find any effect of social status on FCM values in either males or females, as also reported by de Villiers et al. (1997). The categories of social status used in the present study differed from those used in the two former studies - we divided subordinates into those that were unrelated to the opposite sex and those that were (natal born). However, if social status is associated with adrenal activity, the categorisation should not affect the outcome. Considering that social status has been found to influence stress levels in numerous other cooperative breeders (see review in Creel, 2005), the lack of consistency between the three studies of wild dogs is of interest and perhaps caused by variation in pack social structure or behaviour, or perhaps laboratory technique. 
Although stress levels did not differ among stages of the breeding period (when adjusted for social status), the patterns of adrenal activity appeared to differ between the sexes, particularly during the transition from non-breeding to mating. In wild dogs, dominant females usually reproduce in successive years while their sisters and female offspring either disperse or remain with the pack to help rear offspring (Creel and Creel, 2002; Malcom and Marten, 1982; McNutt, 1996). In these circumstances, competition for mates is minimal. This situation was reflected by the apparent reduction in the stress indicator from non-breeding to mating in the subordinate females that were not related to the opposite sex. Conversely, dominant males may be challenged by other adult males during the mating period, leading to aggression and fighting (Creel et al., 1997a; Frame et al., 1979) and consequently stress. Adrenal patterns consistent with this situation were evident in subordinate males that were capable of mating with the unrelated dominant female. Small sample size may have limited the ability to find significant changes in FCM levels, but predictable patterns of adrenal activity was still detected in our study.

The increasing use of faecal glucocorticoid metabolites as a measure of adrenal activity has created a wealth of opportunity for studying the stressful effects of biological and environmental factors on individuals and populations. (Monfort, 2003; Monfort et al., 1997). These studies are highly valuable in addressing conservation concerns of in-situ and ex-situ populations. In particular, understanding how stress affects reproductive health will allow us to address issues in species management, including species that are endangered. In the present study, we were able to derive measures of adrenal activity from individuals of known sex, age and reproductive status, a breadth of factors that is important for drawing conclusions regarding the interaction between stress and reproduction (Millspaugh and Washburn, 2004). For example, the key finding that captive animals produce more FCM than free-ranging animals can inform the process of managing reproductive success for ex-situ populations. Equally, the lack of association of adrenal activity with group housing structure in captive females, and the apparent effects of zoo husbandry, shows that FCM measurements can contribute to improving the management of captive African wild dogs. Similarly, changes in adrenal activity during breeding, and the potential effect of social rank, can aid with timing and choice of individuals for potentially stressful events such as collaring, translocation or re-introductions into free-ranging populations. 


\section{Acknowledgements}

L Van der Weyde was supported by an Australian Postgraduate Award and funding provided by the School of Animal Biology (University of Western Australia) and the Institute for Breeding Rare and Endangered African Mammals (IBREAM). The authors would like to thank Ezemvelo KZN Wildlife for providing permission to conduct research at Hluhluwe-iMfolozi Park (South Africa). They would also like to thank the staff and keepers at Artis Zoo, Perth Zoo, Port Lympne Wild Animal Park, West Midland Safari and Leisure Park and Zoo Duisburg for assistance during faecal collections. Special thanks also go to Margaret Blackberry for advice and assistance in conducting laboratory analyses, Zama Zwane for assistance in the field and Professor Wenche Farstad, Professor Dale Roberts and two anonymous reviewers for helpful comments on the manuscript.

\section{References}

Asa, C.S., 2010. Reproductive physiology, in: Kleiman, D.G., Thompson, K.V., Baer, C.K. (Eds.), Wild Mammals in Captivity: Principles and Techniques. The University of Chicago Press, Chicago, pp. 411428.

Barja, I., Silvan, G., Illera, J.C., 2008. Relationship between sex and stress hormone levels in feces and marking behavior in a wild population of Iberian wolves (Canis lupus signatus). Journal of Chemical Ecology 34, 697-701.

Bhattacharjee, S., Kumar, V., Chandrasekhar, M., Malviya, M., Ganswindt, A., Ramesh, K., Sankar, K., Umapathy, G., 2015. Glucocorticoid stress responses of reintroduced tigers in relation to anthropogenic disturbance in Sariska Tiger Reserve in India. PLOS One 10, DOI:10.1371/journal.pone.0127626.

Carlstead, K., Shepherdson, D., 1994. Effects of environmental enrichment on reproduction. Zoo Biology 13, 447-458.

Comizzoli, P., Crosier, A.E., Songsasen, N., Szykman Gunther, M., Howard, J.G., Wildt, D.E., 2009. Advances in reproductive science for wild carnivore conservation. Reproduction in Domestic Animals 44, 47-52.

Creel, S., 2005. Dominance, aggression, and glucocorticoid levels in social carnivores. Journal of Mammology 86, 255-264.

Creel, S., Creel, N.M., 1991. Energetics, reproductive suppression and obligate communal breeding in carnivores. Behavioral Ecology and Sociobiology 28, 263-270. 
Creel, S., Creel, N.M., 2002. The African Wild Dog: Behavior, Ecology and Conservation. Princeton University Press, Princeton.

Creel, S., Creel, N.M., Mills, M.G.L., Monfort, S.L., 1997a. Rank and reproduction in cooperatively breeding African wild dogs: behavioral and endocrine correlates. Behavioral Ecology 8, 298-306. Creel, S., Creel, N.M., Monfort, S.L., 1997b. Radiocollaring and stress hormones in African wild dogs. Conservation Biology 11, 544-548.

Creel, S., Fox, J.E., Hardy, A., Sands, J., Garrott, B., Peterson, R.O., 2002. Snowmobile activity and glucocorticoid stress responses in wolves and elk. Conservation Biology 16, 809-814.

de Villiers, M.S., Meltzer, D.G.A., Van Heerden, J., Mills, M.G.L., Richardson, P.R.K., Van Jaarsveld, A.S., 1995. Handling-induced stress and mortalities in African wild dogs (Lycaon pictus). Proceedings of the Royal Society of London, Series B 262, 215-220.

de Villiers, M.S., van Jaarsveld, A.S., Meltzer, D.G.A., Richardson, P.R.K., 1997. Social dynamics and the cortisol response to immobilization stress of the African wild dog, Lycaon pictus. Hormones and Behavior 31, 3-14.

Fanson, K.V., Wielebnowski, N., Shenk, T.M., Lucas, J.R., 2011. Comparative patterns of adrenal activity in captive and wild Canada lynx (Lynx canadensis). Journal of Comparative Physiology B 182, 157-165.

Frame, L.H., Malcom, J.R., Frame, G.W., van Lawick, H., 1979. Social organization of African wild dogs (Lycaon pictus) on the Serengeti plains, Tanzania 1967-1978. Zeitschrift Tierpsychologie 50, 225-249. Keay, J.M., Singh, J., Gaunt, M.C., Kaur, T., 2006. Fecal glucocorticoids and their metabolites as indicators of stress in various mammalian species: a literature review. Journal of Zoo and Wildlife Medicine 37, 234-244.

Kenagy, G.J., Place, N.J., 2000. Seasonal changes in plasma glucocorticosteroids of free-living female yellow-pine chipmunks: effects of reproduction and capture and handling. General and Comparative Endocrinology 117, 189-199.

Ladewig, J., 2000. Chronic intermittent stress: a model for the study of long-term stressors, in: Moberg, G.P., Mench, J.A. (Eds.), The Biology of Animal Stress: Basic Principles and Implications for Animal Welfare, 1st Edition ed. CABI Publishing, New York, pp. 160-169.

Malcom, J.R., Marten, K., 1982. Natural selection and the communal rearing of pups in African wild dogs (Lycaon pictus). Behavioral Ecology and Sociobiology 10, 1-13.

Marra, P.P., Lampe, K.T., L, T.B., 1995. Plasma corticosterone levels in two species of Zonotrichia sparrows under captive and free-living conditions. The Wilson Bulletin 107, 296-305. 
Matteri, R.L., Carroll, J.A., Dyer, C.J., 2000. Neuroendocrine responses to stress, in: Moberg, G.P., Mench, J.A. (Eds.), The Biology of Animal Stress: Basic Pinciples and Implications for Animal Welfare, 1st ed. CABI Publishing, Wallingford, UK, pp. 44-76.

McNutt, J.W., 1996. Sex-biased dispersal in African wild dogs, Lycaon pictus. Animal Behaviour 52, 1067-1077.

Millar, R.B., Anderson, M.J., 2004. Remedies for pseudoreplication. Fisheries Research 70, 397-407. Millspaugh, J.J., Washburn, B.E., 2004. Use of fecal glucocorticoid metabolite measures in conservation biology research: considerations for application and interpretation. General and Comparative Endocrinology 138, 189-199.

Moberg, G.P., 1985. Influence of stress on reproduction: measure of well-being, in: Moberg, G.P. (Ed.), Animal Stress. American Physiological Society, Baltimore, pp. 245-267.

Moberg, G.P., 2000. Biological response to stress: implications for animal welfare, in: Moberg, G.P., Mench, J.A. (Eds.), The Biology of Animal Stress: Basic Principles and Implications for Animal Welfare. CABI Publishing, New York, pp. 1-18.

Monfort, S.L., 2003. Non-invasive endocrine measures of reproduction and stress in wild populations, in: Holt, W.V., Pickard, A.R., Rodger, J.C., Wildt, D.E. (Eds.), Reproductive Science and Integrated Conservation. Cambridge University Press, Cambridge, pp. 147-165.

Monfort, S.L., Mashburn, K.L., Brewer, B.A., Creel, S., 1998. Evaluating adrenal activity in African wild dogs (Lycaon pictus) by fecal corticosteroid analysis. Journal of Zoo and Wildlife Medicine 29, 129133.

Monfort, S.L., Wasser, S.K., Mashburn, K.L., Burke, M., Brewer, B.A., Creel, S.R., 1997. Steroid metabolism and validation of noninvasive endocrine monitoring in the African wild dog (Lycaon pictus). Zoo Biology 16, 533-548.

Owen, M.A., Swaisgood, R.R., Czekala, N.M., Steinman, K., Lindburg, D.G., 2004. Monitoring stress in captive giant pandas (Aliuropoda melanoleuca): behavioral and hormonal responses to ambient noise. Zoo Biology 23, 147-164.

Palme, R., 2005. Measuring fecal steroids. Guidelines for practical application. Annals of the New York Academy of Science 1046, 75-80.

Peel, A.J., Vogelnest, L., Finnigan, M., Grossfeldt, L., O'Brien, J.K., 2005. Non-invasive fecal hormone analysis and behavioral observations for monitoring stress responses on captive western lowland gorillas (Gorilla gorilla gorilla). Zoo Biology 24, 431-445.

Rangel-Negrin, A., Alfaro, J.L., Valdez, R.A., Romano, M.C., Serio-Silva, J.C., 2009. Stress in Yucatan spider monkeys: effects of environmental conditions on fecal cortisol levels in wild and captive populations. Animal Conservation 12, 496-502. 
Rivier, C., Rivest, S., 1991. Effect of stress on the activity of the hypothalamic-pituitary-gonadal axis: peripheral and central mechanisms. Biology of Reproduction 45, 523-532.

Santymire, R.M., Armstrong, D.M., 2009. Development of a field-friendly technique for fecal steroid extraction and storage using the African wild dog (Lycaon pictus). Zoo Biology 28, 1-14.

Sapolsky, R.M., 1994. Individual differences and the stress response. Seminars in the Neurosciences 6, 261-269.

Terio, K.A., Marker, L., Munson, L., 2004. Evidence for chronic stress in captive but not free-ranging cheetahs (Acinonyx jubatus) based on adrenal morphology and function. Journal of Wildlife Diseases $40,259-266$.

Tilbrook, A.J., Turner, A.I., Clarke, I.J., 2000. Effects of stress on reproduction in non-rodent mammals: the role of glucocorticoids and sex differences. Reviews of Reproduction 5, 105-113. Touma, C., Palme, R., 2005. Measuring fecal glucocorticoid metabolites im mammals and birds: the importance of validation. Annals of the New York Academy of Science 1046, 54-74.

Van der Weyde, L.K., Martin, G.B., Blackberry, M.A., Gruen, V., Harland, A., Paris, M.C.J., 2015. Reproductive hormonal patterns in pregnant, pseudopregnant and acyclic captive African wild dogs (Lycaon pictus). Animal Reproduction Science 156, 75-82.

Van Meter, P.E., French, J.A., Dloniak, S.M., Watts, H.E., Kolowski, J.M., Holekamp, K.E., 2009. Fecal glucocorticoids reflect socio-ecological and anthropogenic stressors in the lives of wild spotted hyenas. Hormones and Behavior 55, 329-337.

Weingrill, T., Gray, D.A., Barrett, L., Henzi, S.P., 2004. Fecal cortisol levels in free-ranging female chacma baboons: relationship to dominance, reproductive state and environmental factors. Hormones and Behavior 45, 259-269.

Wielebnowski, N.C., Fletchall, N., Carlstead, K., Busso, J.M., Brown, J.L., 2002. Noninvasive assessment of adrenal activity associates with husbandry and behavioral factors in the North American clouded leopard population. Zoo Biology 21, 77-98.

Wingfield, J.C., Sapolsky, R.M., 2003. Reproduction and resistance to stress: when and how. Journal of Neuroendocrinology 15, 711-724. 